\title{
CIDADES MORTAS: O DECLÍNIO DA “CIVILIZAÇÃO CAFEEIRA" NO VALE DO PARAÍBA SEGUNDO A ELITE AGRÁRIA DECADENTE
}

\author{
Luciana Meire da Silva*
}

\begin{abstract}
Resumo: Neste artigo analisamos o conto "Cidades Mortas", escrito por Monteiro Lobato (1882 - 1948) em 1906 e publicado em 1919. Nele o autor descreve os sintomas de decadência da região rural do Vale do Paraíba, denuncia o que chama de "parasitismo" como uma característica do desenvolvimento capitalista brasileiro. Identificamos um narrador perceptivo das perdas de uma fração da burguesia agrária, a qual ele também pertence e a responsabiliza pelos prejuízos e danos causadores do fim da chamada 'civilização do café' na região valparaibana. Ao mesmo tempo, ele observa a expansão cafeeira para a região do Oeste Paulista.
\end{abstract}

Palavras chave: Monteiro Lobato, Brasil Rural, Literatura e Sociedade, Cidades Mortas.

Abstract: In this article we analyse the tale "Dead Cities", written by Monteiro Lobato $(1882-1948)$ in 1906 and published in 1919, in which the author describes the symptoms of decadence in the rural region of Vale do Paraíba and delates what is called "parasitism" as a characteristic of the Brazilian capitalist development. We identified a narrator who realizes the losses of a fraction of the agrarian middle-class, in which he takes part and makes it responsible for the damages that originated the end of what could be called 'coffee civilization' in Vale do Paraíba region, at the same time he observes the coffee expansion towards the Paulista West region.

Keywords: Monteiro Lobato.; Rural Brazil; Literature and Society; Dead Cities.

* Bacharel em Ciências Sociais pela UNESP de Marília/SP, Mestre em Sociologia pela UNESP de Araraquara/SP e doutoranda em Ciências Sociais pela UNESP de Marília/SP, bolsista FAPESP. E-mail: lu.lobato@ig.com.br. 
| 290 |

Cidades Mortas: o declínio da "civilização cafeeira"...

\section{Introdução}

Neste artigo analisamos o texto "Cidades Mortas" escrito por Monteiro Lobato (1882 - 1948) em 1906 e publicado no livro de mesmo nome em 1919. A análise se baseia no levantamento de alguns dos mais importantes aspectos do panorama social, cultural e intelectual. Eles antecedem o Brasil dos anos 20 e fornecem o contexto histórico para o escrito de Lobato, considerado um modernista avant la lettre ${ }^{1}$. Na medida, porém, em que nos propomos trabalhar com literatura e sociedade, lembramos um aspecto fundamental ressaltado por Antonio Candido (1989) em seu ensaio "Literatura de dois gumes":
A criação literária traz como condição necessária uma carga de liberdade que a torna independente sob muitos aspectos, de tal maneira que a explicação dos seus produtos é encontrada sobretudo neles mesmos. Como conjunto de obras de arte, a literatura se caracteriza por essa liberdade extraordinária que transcende as nossas servidões. Mas na medida em que é um sistema de produtos que são também instrumentos de comunicação entre os homens, possui tantas ligações com a vida social, que vale a pena estudar a correspondência e a interação entre ambas (Souza, 1989, p. 161).

Leandro Konder (1992) escreve: “em toda a literatura está presente a fantasia, 'a fuga do real', e ao mesmo tempo, está presente a realidade histórica determinada em que a criação literária se desenvolve. Daí a riqueza de significação que o texto literário chega a ter". Assim um "sociólogo pode ler um romance e interpretá-lo como um documento sociológico" (Konder, 1992, p. 320). É sob essa perspectiva nosso estudo do texto de Monteiro Lobato e entendemos que, mesmo sob forma literária, este autor nos revela questões importantes sobre um período específico do

\footnotetext{
${ }^{1}$ Marisa Lajolo, na obra A modernidade do contra (1985), observa que o escritor já professava preocupação com a modernização do país antes mesmo das manifestações modernistas da década de 1920.
} 
país. E mais, revela a partir de um olhar muito peculiar diferente dos seus contemporâneos literatos. Nossa proposta é desvendar este narrador. Sujeito social divulgador de um Brasil visto com outros olhos pelos simbolistas e modernistas.

Conforme Alfredo Bosi (1966), a característica fortemente nacionalista de Monteiro Lobato, junto com outros autores como: Euclides da Cunha, Graça Aranha e Lima Barreto, deu uma nova expressão ao nacionalismo. Esta expressão já era marcante nos escritores românticos do século XIX, agora com uma nova perspectiva de "expansão" e "revisão crítica", apresentou-se como "um amoroso ressentimento, marcado de pessimismo. De qualquer forma, trata-se de um prelúdio inequívoco do Modernismo" (Bosi, 1966, p. 13) Bosi reconhece, assim, a importância histórica desses autores por movimentarem a "estagnação da 'belle èpoque' trazendo à tona, antes dos modernistas, os conflitos que imperavam na vida nacional" (Bosi, 1992, pp. 345-346).

Durante a primeira metade do século XIX, o Vale do Paraíba se destaca como importante região produtora e exportadora de café, assentada no recrudescimento do trabalho escravista. $\mathrm{Na}$ segunda metade do mesmo século a região, amarga a perda da hegemonia para o Oeste paulista, dinamizador da produção baseada no trabalho assalariado dos imigrantes. Lobato, como "homem de seu tempo e de seu país", para usar uma expressão de Machado de Assis (1955), traz para o leitor sua interpretação dessa transição.

Para dar sequencia ao propósito deste artigo, expusemos uma análise da visão crítica de Monteiro Lobato sobre a exploração da monocultura cafeeira na região do Vale do Paraíba. Ele afirma que o "nosso progresso é nômade e sujeito a paralisias súbitas", sobressai a ideia de um mal inesperado compensado com o nomadismo. Esse nomadismo, na crítica de Monteiro Lobato, é uma característica do processo de produção agrícola no Brasil causado pela abundância das terras e pelo desenvolvimento capitalista. Em seguida analisamos o ponto de vista do autor sobre as cidades que viveram o apogeu e posteriormente o declínio 
| 292 |

Cidades Mortas: o declínio da "civilização cafeeira"...

no rastro do café. O texto de Monteiro Lobato percorre as ruas desertas das cidades decadentes da região do Vale do Paraíba onde raramente se ouve o ruído dos carros de boi, uma alusão aos tropeiros, circulantes das mercadorias e produtos naquelas paragens. Fazendo eco à desertificação das vias, permanecem os imensos casarões abandonados e da opulência apenas as imagens arruinadas. Ao final, apresentamos a visão de Monteiro Lobato sobre a decadência dos fazendeiros valparaibanos. Os salões antigamente refinados com ornamentos e ostentações luxuosas, motivo de orgulho e reunião da antiga elite cafeicultora, hoje, vazios, apenas atestam o tempo próspero de outrora.

\section{A visão crítica da monocultura cafeeira}

Ao iniciar o conto Cidades Mortas, Monteiro Lobato coloca para o leitor suas impressões sobre a decadência cafeeira no Vale do Paraíba. Ao criticar as características do desenvolvimento brasileiro, chama-o de "progresso cigano", realizado sob a exploração da terra através da monocultura do café. Na sua visão teria sido o causador da estagnação da região. Em todo o texto, o autor observa o embate entre atraso e progresso, passado e presente, Vale do Paraíba e Oeste Paulista. Seu modo de pensar pode ser explicado pelo contraponto feito pelo autor entre os dias de glória e bonança vividos no passado e a escassez do presente como uma característica do "progresso cigano".

No conto Cidades Mortas, este olhar narrativo diagnostica a decadência da cafeicultura na região do Vale do Paraíba e decreta a sua morte. Isso é evidenciado em sua afirmação: “umas tantas cidades moribundas arrastam um viver decrépito". A expressão Cidades Mortas nos dá a ideia de algo morto, estagnado. Portanto, uma visão decadentista e mórbida sobre os destinos da região abordada.

A quem em nossa terra percorre tais e tais zonas, vivas outrora, hoje mortas, ou em via disso, tolhidas de insanável caquexia, uma verdade, que é um desconsolo, ressurge de tantas ruínas: nosso progresso é nômade e 
sujeito a paralisias súbitas. Radica-se mal. Conjugado a um grupo de fatores sempre os mesmos, reflui com eles duma região para outra. Não emite peão. Progresso de cigano vive acampado. Emigra, deixando atrás de si um rastilho de taperas (Lobato, 1995, p. 22).

Mais adiante, podemos ler que, segundo quem fala, a região está morta e não há mais recursos para sanar sua paralisia. Nas suas palavras, essas zonas estão "tolhidas de insanável caquexia". Não há mais perspectivas de melhoria ou superação da decadência. A imagem restante é a de um deserto: “De banda a banda, o deserto - o tremendo deserto que o Átila café criou" (Lobato, 1995, p. 24).

Podemos dizer também que esse narrador sempre se reporta ao passado, relembra os velhos tempos quando, segundo ele, essas cidades eram vivas. $O$ contraste entre passado e presente se verifica quando o narrador, ao falar do presente, observa-o a partir do passado, o seu referencial de bons tempos. Por isso, sob seu olhar, o tempo corrente é visto, como perdedor, e a narrativa se faz trágica: “Em São Paulo, temos perfeito exemplo disso na depressão profunda que entorpece boa parte do chamado Norte. / Ali tudo foi, nada é. Não se conjugam verbos no presente. Tudo é pretérito" (Lobato, 1995, p. 21).

A expressão "ali tudo foi, nada é", constitui uma afirmação categórica do fim e da estagnação dessa região agrária produtora da monocultura cafeeira.

\section{Cidades com apogeu e declínio no rastro do café}

Monteiro Lobato critica quem chora as perdas sociais dessas "cidades mortas", mas ele também está inserido nesse contexto, e igualmente lamenta os prejuízos de sua classe social: os fazendeiros de café decadentes da região do Vale do Paraíba, outrora prósperos e ostentadores das riquezas. A observação feita por ele: é o viver nessas cidades se resume "em chorar na mesquinhez de 
| 294 |

Cidades Mortas: o declínio da "civilização cafeeira"...

hoje as saudosas grandezas de dantes" (Lobato, 1995, p. 21).

Por que esse narrador social fala, a partir da decadência? Podemos entender que, ao declarar a morte da agricultura cafeeira na região valparaibana, ele revela as impressões de uma fração daquela elite: ela já não tem mais perspectivas como classe dominante.

O narrador critica as características do desenvolvimento capitalista brasileiro: "nosso progresso é nômade e sujeito à paralisias súbitas". As expressões "progresso nômade" e "paralisias súbitas" são para explicar que, do seu ponto de vista, nosso desenvolvimento não se concretiza definitivamente: "Radica-se mal", diz ele de uma atividade econômica passageira e sem raízes. Na sua visão, ela é deficiente e se compensa com o nomadismo, esgota-se em uma região e muda para outra: "conjugado a um grupo de fatores sempre os mesmos, reflui com eles duma região para outra" (Lobato, 1995, p. 21).

Ao mesmo tempo, o narrador diagnostica a decadência e se mostra desconsolado com ela: "uma verdade que é um desconsolo, ressurge de tantas ruínas: nosso progresso é nômade e sujeito a paralisias súbitas" (Lobato, 1995, p. 21).

O narrador social se mostra saudoso dos tempos prósperos e cheios de glória. Critica o choro dos fazendeiros, mas ele mesmo faz parte dessas lamúrias e lamentações. Lastima com tristeza o estado atual das antigas fazendas, escreve num tom de profunda morbidez:

As fazendas são Escórias de soberbo aspecto vistas de longe, entristecedoras quando se lhes chega ao pé. Ladeando a casa grande, senzalas vazias e terreiros de pedra com viçosas guanxumas nos interstícios... cafezais extintos, agregados dispersos (Lobato, 1995, p. 24).

Além da lamúria presente em todo o texto, ele fala com saudade da fazenda dinâmica e produtiva. Mas, de uma forma sutil, lamenta também o fim de uma era estruturada no braço escravo. A atividade das senzalas, agora vazias, completa a ideia de que a época das fazendas sustentadas pela escravatura foi um grande 
tempo, sempre presente em seu pensamento: "Ladeando a casagrande, senzalas vazias...".

É importante chamar a atenção para este aspecto passadista do pensamento de Lobato neste seu texto de 1906. Observamos que, aquele que seria depois chamado de modernista, neste momento, tem um olhar fortemente decadentista e trágico, revela uma característica típica da elite agrária brasileira que se julgava eterna. Mas, ao mesmo tempo, Lobato já dá mostras do seu pensamento futuro quando defende um projeto de desenvolvimento agrário para o país como a melhoria da fertilidade das terras por intermédio do adubo. Ao reclamar das características do desenvolvimento brasileiro, observa que além do "progresso cigano", outro fator contribuinte à decadência da economia agrária na região do Vale do Paraíba foi a falta de um tratamento adequado e racional do solo. Segundo ele, a fertilidade natural do solo pode levar ao desenvolvimento, mas tal fato não acontece:

$$
\begin{aligned}
& \text { (...) mal a uberdade se esvai, pela reiterada sucção } \\
& \text { de uma seiva não recomposta, como no velho } \\
& \text { mundo, pelo adubo, o desenvolvimento da zona } \\
& \text { esmorece, foge dela o capital - e com ele os homens } \\
& \text { fortes aptos para o trabalho. E lentamente cai a } \\
& \text { tapera nas almas e nas coisas. (Lobato, 1995, p. 21) }
\end{aligned}
$$

A decadência tomou conta da região, pois não existiu interesse por parte dos fazendeiros na recomposição dos nutrientes do solo através da racionalidade técnica, prática utilizada pelas nações desenvolvidas da Europa. Portanto, podemos dizer que, nesta sua observação, o escritor pensa que se houvesse tido investimentos na lavoura para a recuperação da fertilidade das terras, a situação seria outra: “Toda a seiva foi bebida e, sob forma de grão, ensacada e mandada para fora. Mas do ouro que veio em troca nem uma onça permaneceu ali, empregada em restaurar o torrão" (Lobato, 1995, p. 23).

Pode-se dizer que, também se reclama aqui, uma adaptação da sociedade brasileira ao "progresso" cujo modelo era as nações mais desenvolvidas. E, nesse sentido, Lobato faz coro com os 
| 296 |

Cidades Mortas: o declínio da "civilização cafeeira"...

ruralistas "ilustrados" da Primeira República, segundo Mendonça (1993) defensores de uma "regeneração agrícola para o país" eles emitem suas considerações sobre a crise: "auto-intitulando-se guias paladinos da classe agrícola". (Mendonça, 1993, p. 26) Também devido ao estado da crise agrícola nos primeiros anos da República, o fio condutor dos debates ruralistas do período foi a "modernização da agricultura e a maximização da produtividade dos empreendimentos agrários" (Mendonça, 1993, p. 26).

Mas, para o narrador do conto de Lobato, o rural do Vale já está decadente e não existe mais possibilidade de recuperá-lo. Certamente porque muito da grandeza da cafeicultura dessa região estava fundamentada numa base produtiva não reabilitada: a mão de obra escrava.

\section{Decadência dos fazendeiros - uma fração da elite cafeicultora perde sua hegemonia}

Em Cidades Mortas, as ruas estão escuras e sombrias e segundo quem fala, os decrépitos "casarões apalaçados" designam a antiga civilização cafeeira. Os casarões estão lá apenas para comprovação de um tempo próspero. Podemos interrogar que prosperidade era essa, definida por signos pelo narrador:

Pelas ruas ermas, onde o transeunte é raro, não matracoleja sequer uma carroça; de há muito, em matéria de rodas, se voltou aos rodízios desse rechinante símbolo do viver colonial - o carro de boi. Erguem-se por ali sóbrios casarões apalaçados, de dois e três andares - sólidos como fortalezas, tudo pedra, cal e cabiúna; casarões que lembram ossaturas de megatérios donde as carnes, o sangue, a vida para sempre refugiram (Lobato, 1995, p. 22).

A ideia de permanência aparece em "sóbrios casarões apalaçados... sólidos como fortalezas...". Essas expressões nos dão a ideia de como a elite cafeeira se considerava eterna e imbatível. 
Mas, logo adiante, o próprio narrador nos oferece o diagnóstico: parte dessa grandeza da elite cafeicultora era ostentação:

\begin{abstract}
Erguem-se por ali soberbos casarões apalaçados, de dois e três andares, sólidos como fortalezas, tudo pedra, cal e cabiúna; casarões que lembram ossaturas de magatérios donde as carnes, o sangue, a vida para sempre refugiram. / Pelos salões vazios, cujos frisos dourados se recobrem da pátina dos anos e cujo estuque, lagarteado de fendas, esboroa à força de goteiras, paira o bafio da morte. Há nas paredes quadros antigos, crayons, figurando efígies de capitães-mores de barba em colar (Lobato, 1995, p. 22).
\end{abstract}

Ao observar os salões refinados, com os seus objetos e aparatos no passado, motivo de orgulho da elite cafeicultora, no presente apenas a confirmação de um tempo próspero. Segundo Campos (1986), essa elite importou hábitos, costumes e ideias da Belle Époque parisiense.

Para ilustrar essa questão da ostentação do luxo importado, da exaltação em aparências do poder de mando dos fazendeiros, citamos Hernâni Donato (1950) em Filhos do Destino. Ao falar da expansão do café para o Oeste Paulista, observa a reiteração do mesmo estilo já visto no Vale do Paraíba:

Mil novecentos e dezenove. A zona do café. A época do café. Tempo milionário da invasão vegetal. O café rompeu todas as comportas e dominou o Estado. Dois bilhões de cafeeiros alinham-se na planície. Jamais em qualquer tempo ou país, o homem criara uma cultura tão vasta. Tudo cede diante do café e para qualquer lado que se vá ou se olhe, é sempre ele que se apresenta. Os donos da terra rivalizam no luxo. Mandam buscar na capital por cifras alucinantes as novidades da técnica e do conforto. Toda a gente guarda dinheiro e adquire vícios. Os cafeicultores não pedem. São os senhores do país. Ordenam. Deus dá o fazendeiro distribui. A política é feita nos alpendres das 'casas de fazenda' (apud Ellis, 1976, p. 144). 
| 298 |

Cidades Mortas: o declínio da "civilização cafeeira"...

Pode-se inferir dessa citação que o autor fala da situação específica do Oeste Paulista. Como se vê, não deixou de ser constituída com os mesmos elementos, ou com a mesma ética de classe, agora transportada do Vale do Paraíba para outra região do estado.

$\mathrm{E}$, para esse setor que fundamentalmente não dispensava a ostentação e o luxo, como elementos intrínsecos ao poder de classe, junto aos prejuízos econômicos sobrevêm as lamentações das perdas sociais e também um viver mesquinho, como observam nosso narrador e também outros escritores sobre o Oeste paulista:

\footnotetext{
Vivem dentro, mesquinhamente, vergônteas mortiças de famílias fidalgas de boa prosápia entroncada na nobiliarquia lusitana. Pelos salões vazios, cujos frisos dourados se recobrem da pátina dos anos e cujo estuque, lagarteado de fendas, esboroa à força de goteiras, paira o bafio da morte. Há nas paredes quadros, crayons, figurando efígies de capitães-mores de barba em colar (Lobato, 1995, p. 22).
}

Monteiro Lobato fala, com certa ironia, mas também com um sentimento de tragédia, daqueles que se consideravam uma classe superior e se orgulhavam por pertencerem às famílias dos quatrocentões e então passaram a amargar um viver mesquinho.

Nas entrelinhas, há um narrador declarador da morte social, econômica e política dessa classe. Os salões refinados, com a ostentação do passado, motivo de orgulho da elite cafeicultora, apenas confirmam um tempo de glória no qual o 'chic' era importar moda francesa. Mas a morte tomara conta de todos inclusive dos antigos barões do café, figurantes nos quadros das paredes. Ninguém mais se lembra de seus nomes e feitos. Esse fato já fazia parte do 'Brasil Velho' e o narrador quer vê-lo superado, embora ele mantenha certo sentimento de nostalgia, como vimos em outras partes do conto: "Há sobre os aparadores Luis XV brônzeos candelabros de dezoito velas, esverdecidos de azinhavre. Mas nem se acendem as velas, nem se guardam os nomes dos enquadrados 
- e por tudo se agruma o bolor râncido da velhice" (Lobato, 1995, p. 22).

A ideia de "bolor râncido da velhice" carrega a proposta de passado e não exatamente de tradição. Um passado como o país se apresentava, sem condições de fazer parte do futuro: o "progresso cigano" deixa rastros de destruição e o deserto se faz irreversível. Onde está essa elite agrária decadente representada por Lobato como perdedora? O próprio autor responde: “... o dono está no Rio, em São Paulo, na Europa" (Lobato, 1995, p. 24). As perdas aconteceram somente na produção cafeeira, isto porque, essa elite, com as influências políticas e sociais exercidas, acabava por encontrar meios para sobreviver. Um exemplo são os bacharéis que Lobato critica ao chamá-los de "sinecuristas acarrapatados ao orçamento: juiz, coletor, delegado" (Lobato, 1995, p. 22).

Assim também, esta era a condição do próprio Lobato: herdara por influência do avô, o cargo ocupado². Ao mesmo tempo, ao criticar o que chama de "pátria do bacharelismo" referindo-se àqueles que exercem cargos públicos e "ganham ser fazer nada", o próprio Lobato, segundo Campos (1986) recebeu uma nomeação como promotor público na cidade de Areias em 1907: “A cavação da promotoria como o próprio Lobato definiu, deveu-se às relações de sua família com o então Secretário de estado, Washington Luiz" (Campos, 1986, p. 10).

\footnotetext{
${ }^{2}$ Sobre a conquista da promotoria, em carta ao amigo Rangel datada em abrilde 1907, Lobato escreveu: “O meu atraso epistolar tem origem na "cavação de promotoria" em que me empenhei em fevereiro e só agora, 4 de março, consegui levar a efeito, com derrota de um exército de candidatos. Estou nomeado promotor público da comarca de Areias, que deve ser nalgum lugar. Mais reverê

ncia, portanto, amigo, quando escreveres ao Lobato. Exijo DD. no envelope. Sou o DD. Promotor Público de Areias, cidade que positivamente há de existir. Cento e tantos candidatos para esse ossinho - informou-me o próprio secretário Washington Luis (com "s" - ele faz questão). Foi trunfo decisivo uma carta de meu avô ao general Glicério..." (Lobato, 1964, pp. 158-159).
} 
$|300|$

Cidades Mortas: o declínio da "civilização cafeeira"...

Portanto, era uma prática comum às famílias da oligarquia cafeicultora (agora, em especial, a decadente) a "pressão" através das influências políticas e sociais, das relações de favores e dependência tão comum à história brasileira para obtenção de empregos públicos. Como Lobato escreve este tipo de coisas lhe desgostava, mas a situação parecia insuperável neste momento: uma prática social e política de classe. Há uma forte crítica à lógica da exploração capitalista na sociedade rural brasileira nos primeiros anos da República, mesmo sem o horizonte de um projeto de nação.

Mas, se tomarmos o pequeno texto de Lobato chamado "Vidinha ociosa", publicado em Cidades Mortas, veremos uma particularidade em sua perspectiva: ele vê com olhos críticos a classe proprietária e sugere a incapacidade de pensar de maneira racional dos velhos fazendeiros.

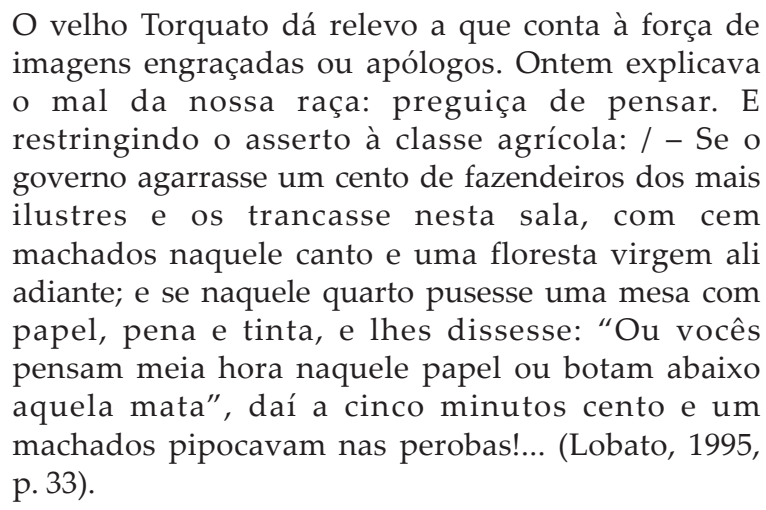

Os velhos fazendeiros até podiam ser empreendedores (derrubarem a mata - coisa que certamente ordenariam para ser feita, pois a elite proprietária tinha o trabalho manual em má consideração), mas não são muito acostumados à racionalidade e ao planejamento nos empreendimentos agrários. Em outro texto, Lobato compara o fazendeiro ao Jeca Tatu, para ele o retrato do parasitismo, acomodado por excelência. 
Quer dizer, há uma crítica do autor ao estado de coisas, mas não há meio de ver no horizonte uma saída. Por isso, terminará o texto elogiando o café - o "Átila café" destruidor da uberdade do solo - na sua forma assumida na região do Oeste paulista:

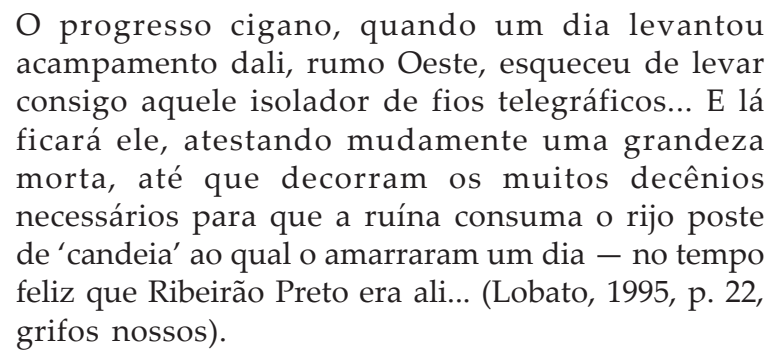

Que rural é esse visto em Lobato? De um lado a experiência de perda da fração cafeicultora do Vale do Paraíba: ela encontra um jeito de sobreviver a partir das antigas influências. Perde economicamente, mas garante espaço no estado através de cargos públicos, tal como aquele ocupado pelo próprio escritor valparaibano. O "outro" rural é o da região Oeste de São Paulo, representado como capaz de fazer uma trajetória diferente da exploração do Vale do Paraíba, esta marcada pela mão de obra livre, ao contrário do proprietário escravista da região descrita por Monteiro Lobato.

Ribeirão Preto, o novo "lugar" do café, promete uma nova forma de exploração no oeste do estado? "Transfiltrou-se para oeste", mas, a "felicidade" também será cigana, como o progresso falado por Lobato no início deste texto.

A história mostraria a pátria do café e do bacharelismo ainda dominante até 1930. A morbidez, o fim de era perpassada pelo texto de Lobato não significa a morte dessa elite. Ela parece ter se restringido as imagens tétricas: os casarões em ruínas, as senzalas vazias, os lustres apagados, os salões vazios, os cafezais extintos. Pois, os seus antigos donos estão em São Paulo, no Rio ou na Europa. 
|302|

Cidades Mortas: o declínio da "civilização cafeeira"...

Existe outro lado neste abandono e Monteiro Lobato o descreve com a mesma morbidade, e com certo desdém: a sorte dos trabalhadores e das pessoas pobres moradoras destas cidades, com sua vida econômica e social totalmente dependente da produção cafeeira.

Avultam em números, nas ruas centrais, casas sem janelas, só portas três e quatro: antigos armazéns hoje fechados, porque o comércio desertou também. Em certa praça vazia, vestígios vagos de 'monumento' de vulto: o antigo teatro - um teatro onde já ressoou a voz de Rossina Stolze, de Candiani... / Não há na cidade exangue nem pedreiros nem carapinas; fizeram-se estes remendões; aqueles, meros demolidores - tanto vai da última construção. A tarefa se lhes resume em especar muros que deitam ventre, escorar paredes rachadas e remendá-las mal e mal. Um dia metem abaixo as telhas: sempre vale trinta mil-réis o milheiro - e fica à inclemência do tempo o encargo de aluir o resto (Lobato, 1995, p. 22).

Tudo dependente efetivamente da monocultura do café fica à deriva. Os trabalhadores ficam sem as suas atividades profissionais e padecem as perdas nas "cidades mortas". Os fazendeiros migrantes junto com o fim da fertilidade e exploração do braço escravo não parecem sofrer as demais consequências nas relações de sociabilidade:

Da geração nova, os rapazes debandam cedo, quase meninos ainda; só ficam as moças - sempre fincadas de cotovelos à janela, negaceando um marido que é um mito em terra assim, onde os casadouros fogem. Pescam, às vezes, as mais jeitosas, o seu promotorzinho, o seu delegadozinho de carreira - e o caso vira prodigioso acontecimento histórico, criador de lenda (Lobato, 1995, p. 22).

Aqui o tom de Lobato não é mais de penúria, mas de ironia. A situação das famílias "fidalgas de boa prosápia" é a da grande 
perda, pois são ou foram donos dos "palácios mortos das cidades mortas". Em contraste, a situação das moças que dependiam do casamento para alçar qualquer posição social é digna de riso: tentam "pescar" um marido entre os funcionários públicos que por força das circunstâncias permanecem ou migram para a cidade. A vida das cidades do Vale dependia da produção agro-exportadora, tudo dependia e girava em torno do café: a vida do teatro, as construções e também a sociabilidade. Portanto o cafeicultor exercia um poder ampliado através do patriarcalismo, pois dele dependia indiretamente até o bom casamento para as moças do lugar.

A situação dos pobres é vista com certa ironia e "desconfiança" que denuncia um olhar de classe além das influências naturalistas e racistas dos escritos da década de 10:

O resto é a 'mob': velhos mestiços de miserável descendência, roídos de opilação e álcool; famílias decaídas, a viverem misteriosamente umas, outras à custa do parco auxílio enviado de fora por um filho mais audacioso que emigrou. 'Boa gente', que vive de aparas (...) Cafezais extintos. Agregados dispersos. Subsistem unicamente, como lagartixas na pedra, um pugilo de caboclos opilados, de esclerótica biliosa, inermes, incapazes de fecundar a terra, incapazes de abandonar a querência, verdadeiros vegetais de carne que não florescem nem frutificam - fauna cadavérica de última fase a roer os derradeiros capões de café escondidos nos grotões (Lobato, 1995, p. 22).

A "mob" é o restante, de miserável descendência, assim como os "caboclos opilados" e "incapazes de fecundar a terra". Deste modo, a população pobre no Brasil oligárquico, fosse rural ou urbana, só existia à sombra do vigor da produção da monocultura cafeeira, dependente da grande propriedade e da elite cafeicultora. Caso contrário, seriam como "lagartixas na pedra" ou "verdadeiros vegetais de carne". Nesse trecho, como também nos artigos "Velha Praga" e "Urupês" escritos em 1914 e publicados em 1918 no livro 
Urupês, Monteiro Lobato chama a atenção para o problema da mão de obra nacional. $\mathrm{O}$ autor considera o trabalhador brasileiro como uma sub-raça, indolente e um "piolho da terra". Ele sobrevive, em alguns casos, das últimas gotas do café "escondidas nos grotões". Este narrador sugere que, ao extinguir a produção cafeeira, extingue-se também, as pessoas dependentes dela.

Monteiro Lobato se revela como parte da elite cafeicultora decadente, como um narrador de classe. Os trabalhadores, a gente pobre serve à propriedade, aos seus caprichos ciganos. Mas tais pessoas não fazem parte da tragédia da grande perda. Então quem perde realmente? Se a elite migrou assim como o café, podemos dizer que os pobres, os trabalhadores, as moças casadouras, os velhos caboclos opilados, os velhos mestiços são os que fazem parte das "cidades mortas", junto com os armazéns fechados, os salões vazios apenas atestam o declínio, com seus candelabros apagados e os palacetes em ruínas.

\section{Bibliografia}

ASSIS, M. de. Literatura Brasileira - Instinto de nacionalidade. Obras Completas de Machado de Assis Crítica Literária. Rio de Janeiro, São Paulo, Porto Alegre: W. M. Jackson Editora, 1955.

BOSI, A. História concisa da literatura brasileira. São Paulo: Editora Cultrix, 1992. . O pré-modernismo. São Paulo: Editora Cultrix. 1966.

CAMPOS, A. L. A República do Picapau Amarelo. São Paulo: Martins Fontes, 1986.

ELLIS, M. O Café literatura e história. São Paulo: Edições Melhoramentos, Editora da Universidade de São Paulo, 1976.

KONDER, L. "A sabedoria Humilde na Firmeza do engajamento". In: D'Incao e Scarabôtolo (orgs.). Dentro do texto, dentro da vida: ensaios sobre Antonio Candido. São Paulo: Companhia das Letras e Instituto Moreira Salles, 1992. 
LAJOLO, M. Lobato: A modernidade do contra. São Paulo: Editora Brasiliense, 1985.

LOBATO, M. A Barca de Gleyre, v. I, 11 a ed. São Paulo: Editora Brasiliense, 1964. 1995 .

Cidades Mortas, $8^{a}$ ed. São Paulo: Editora Brasiliense,

Urupês. $1^{\mathrm{a}}$ ed. rev., $2^{\mathrm{a}}$ reimpressão. São Paulo: Editora Brasiliense,1997.

MENDONÇA, S. R. de. “O ruralismo brasileiro na Primeira República: Um debate de ideias". In: À Margem Revista de Ciências Humanas, ano I, janeiro quadrimestral, pp. 25-40, 1993.

SOUZA, A. C. de M. e. A Educação pela noite e outros ensaios. $2^{\text {a }}$ ed. São Paulo: Editora Ática,1989.

STOLKE, V. Cafeicultura: Homens, mulheres e capital (1850-1980). São Paulo: Editora Brasiliense,1986. 